\title{
A MODIFICATION FOR ROUTINE LABORATORY USE OF STEFANINI'S METHOD OF ESTIMATING FACTOR V ACTIVITY IN HUMAN OXALATED PLASMA
}

BY

\author{
PETER WOLF \\ From the Department of Pathology, Crumpsall Hospital, Manchester
}

(RECEIVED FOR PUBLICATION JULY 7, 1952)

Quick and Stefanini in 1948 introduced a method for estimating the activity of factor $\mathrm{V}$ (Owren, 1947a) in human and animal oxalated plasma. This factor is also known as the labile factor (Quick, 1947) and prothrombin A (Quick, 1943). Stefanini's modification of this method is fully described in a later paper (Stefanini, 1951). The essential steps in this modified method are that factor-V-deficient plasma is prepared by storing human oxalated plasma for 15 to 25 days at $4^{\circ} \mathrm{C}$. Using this plasma, a dilution curve of factor $\mathrm{V}$ activity for an average normal plasma is constructed by adding $0.09 \mathrm{ml}$. of the stored plasma to $0.01 \mathrm{ml}$. of the normal plasma, which has been diluted with $0.85 \%$ saline to strengths varying from $10 \%$ to $100 \%$ at $10 \%$ intervals. A Quick's onestage prothrombin estimation is then performed on $0.1 \mathrm{ml}$. of each of these mixtures and the percentage strength of the fresh plasma (or concentration of factor $\mathrm{V}$ ) is plotted against the clotting time in seconds, when a characteristic curve is obtained. This curve may then be used to estimate the factor $\mathrm{V}$ activity of a test plasma. The clotting time is obtained using Quick's one-stage prothrombin test for a mixture of $0.01 \mathrm{ml}$. of the test plasma with $0.09 \mathrm{ml}$. of stored plasma, and the resulting time is compared with the curve to find the corresponding factor $\mathrm{V}$ activity.

In our hands this technique produced unsatisfactory results for the following reasons:

\footnotetext{
* Quick's one-stage prothrombin test is done in this laboratory rsing 0.2-ml. quantities as described by Owren (1947b). Human brain extract instead of rabbit brain is used as the source of thromboplastin. This powder is stored in a desiccator in a sealed tube and when required $0.32 \mathrm{~g}$. is warmed with $0.6 \mathrm{ml}$. of $0.85 \%$ saline for 15 minutes at $50^{\circ} \mathrm{C}$. The temperature is not allowed to rise above $50^{\circ} \mathrm{C}$. as this would impair the activity of the resulting thromboplastin. The strength of the calcium chloride solution used is $0.02 \%$. With the present batch of thrombop!astin the clotting occurs for normal controls between 10 and 11 seconds after adding the calcium chloride solution.
}

Storage of normal plasmas for 15 to 25 days at $\rightarrow$ $4^{\circ} \mathrm{C}$. produced widely varying and inadequate $T_{\mathbb{D}}$ prolongations of the clotting time by Quick's one- 을 stage prothrombin test* (Table I). (2) During storage many of the plasmas became cloudy due to deposition of albumin and fibrin. (3) There is $\vec{c}$ a considerable risk of plasma stored for this length of time becoming infected. (4) Storage of plasma for so long was found to be cumbersome and inconvenient for routine laboratory use. (5) When the dilution curve was plotted using $0.18 \mathrm{ml}$. of stored plasma with $0.02 \mathrm{ml}$. of fresh plasma of $\mathbb{D}$ varying dilutions a smooth curve was never obtained, for example, as shown in Fig. 2. The 욱 error was thought to be due to the unsatisfactory degree of accuracy in measuring quantities of $0.02 \mathrm{ml}$. The dilution ratio of $9 \mathrm{vol}$. of incubated plasma to 1 vol. of fresh plasma could not be? obtained by mixing larger quantities because of the limited quantity of plasma normally available.

In an attempt to remedy these defects the following modifications were made to the technique employed by Stefanini, and these were found to을 give a more sensitive and a smoother dilution $>$ curve (Fig. 1). Instead of the factor-V-deficient plasma being prepared by storing human oxalated plasma for 15 to 25 days at $4^{\circ} \mathrm{C}$. it was made by ${ }^{\circ}$ incubating fresh normal oxalated plasma at $37^{\circ} \mathrm{N}$ C. for 24 hours. This provided a more efficient $\mathbb{W}^{N}$ source and eliminated errors due to infection oro

TABLE I

DECREASE IN CLOTTING ABILITY OF NORMAL FRESH PLASMAS TREATED IN TWO WAYS

\begin{tabular}{|c|c|c|c|}
\hline $\begin{array}{c}\text { Experi- } \\
\text { ment }\end{array}$ & $\begin{array}{c}\text { Clotting Time of } \\
\text { Fresh Plasma by } \\
\text { Quick's One-stage } \\
\text { Test }\end{array}$ & $\begin{array}{l}\text { Clotting Time of } \\
\text { Plasma after } \\
\text { Storage at } 4^{\circ} \mathrm{C} . \\
\text { for } 15 \text { Days }\end{array}$ & $\begin{array}{l}\text { Clotting Time of } \\
\text { Plasma after } \\
\text { Incubation at } \\
37^{\circ} \mathrm{C} \text {. for } 24 \text { Hours }\end{array}$ \\
\hline $\begin{array}{l}1 \\
2\end{array}$ & $\begin{array}{l}10 \text { seconds } \\
10.5 \quad,\end{array}$ & $\begin{array}{c}14 \text { seconds } \\
17\end{array}$ & $\begin{array}{cc}29 & \text { seconds } \\
31 & . .\end{array}$ \\
\hline
\end{tabular}


deposition of fibrin and albumin ; also it was found to be more convenient. The clotting time of an average normal plasma with a $100 \%$ prothrombin complex concentration, using Quick's one-stage prothrombin test, was between 10 and 10.5 seconds with the batch of thromboplastin then in use. After the plasma has been incubated for 24 hours at $37^{\circ} \mathrm{C}$. the clotting time by this method is extended to between 29 and 35 seconds, which is a more satisfactory result than that obtained by storage (Table I). Reasons for believing that this plasma is deficient in factor $\mathrm{V}$ and not in any other clotting factor are dealt with later.

In plotting the dilution curve, water instead of $0.85 \%$ saline was used as the diluting agent because the dilution curves so obtained showed greater sensitivity to minor degrees of factor $\mathbf{V}$ deficiency. This was observed in a number of cases when similar curves were plotted using the two diluting agents. An example of the difference in the curves so obtained can be seen by comparing Fig. 1, in which water was used as diluting agent, with Fig. 3, in which saline was used. Saline is not considered to be a physiological diluting fluid because it is known to have an anticoagulant effect (Owren, 1947c ; Quick, 1936). Plasma which has been passed through a Seitz filter containing $30 \%$ to $40 \%$ asbestos* has an electrolyte composition similar to that found in the body so may

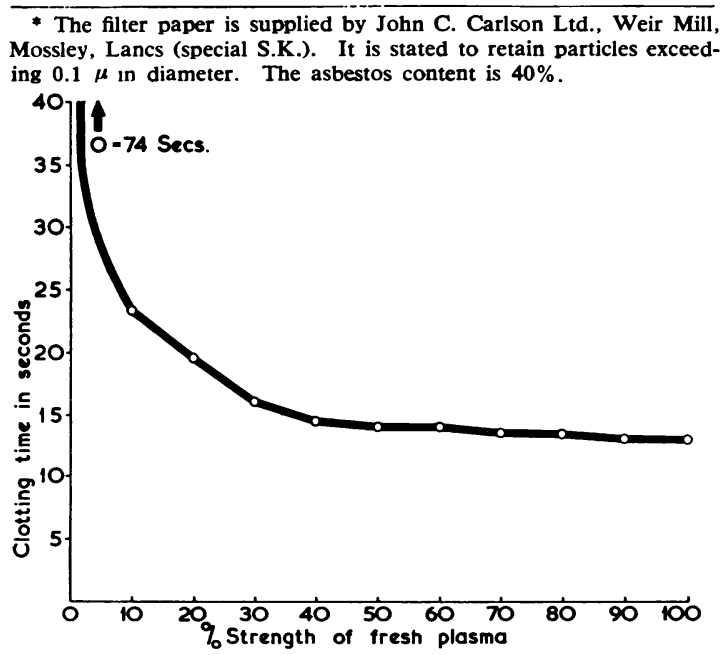

\begin{tabular}{l|r|c|c|c|c|c|c|c|c|c}
\hline $\begin{array}{l}\text { \% strength of fresh } \\
\text { plasma }\end{array}$ & 100 & 90 & 80 & 70 & 60 & 50 & 40 & 30 & 20 & 10 \\
$\begin{array}{c}\text { Clotting time in } \\
\text { seconds }\end{array}$ & 13 & 13 & $13 \cdot 5$ & $13 \cdot 5$ & 14 & 14 & $14 \cdot 5$ & 16 & $19 \cdot 5$ & $23 \cdot 5$ \\
\hline
\end{tabular}

FIG. 1.-Clotting times using $0.1 \mathrm{ml}$. of incubated plasma with $0.1 \mathrm{ml}$. of fresh plasma of varying dilutions in water. Clotting time of fresh plasma $=10.5 \mathrm{sec}$; clotting time of incubated plasma= $74 \mathrm{sec}$. be considered to be a physiological diluting fluid, and since water reacted similarly it was considered preferable to saline as a diluting agent for this work.

Instead of plotting the dilution curve using 9 vol. of stored plasma with 1 vol. of fresh normal plasma of varying dilutions, equal volumes of incubated and fresh plasma were used, i.e., $0.2 \mathrm{ml}$. of incubated plasma was added to $0.2 \mathrm{ml}$. of fresh, normal plasma at each dilution, and $0.2 \mathrm{ml}$. of this mixture was used to obtain the clotting time by Quick's one-stage prothrombin test. The curve
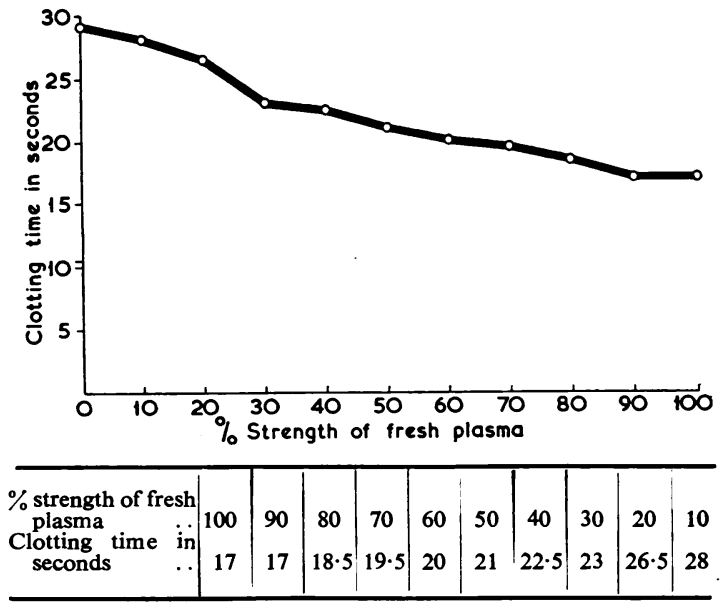

Fig. 2. Clotting times using $0.18 \mathrm{ml}$. of incubated plasma with $0.02 \mathrm{ml}$. of fresh plasma of varying dilutions in normal saline: clotting time of fresh plasma $=9.5 \mathrm{sec}$; clotting time of incubated plasma $=29$ sec.
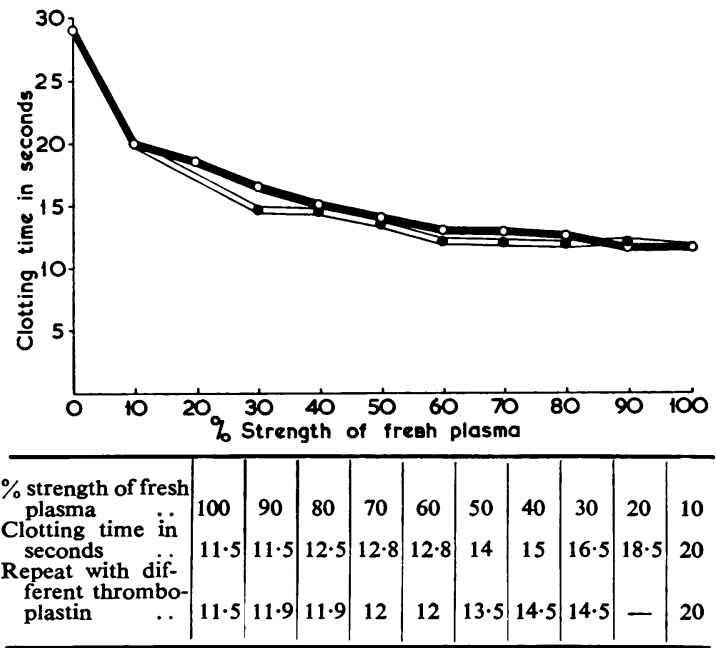

Fig. 3.-Clotting times using $0.1 \mathrm{ml}$. of incubated plasma with $0.1 \mathrm{ml}$. of fresh plasma of varying dilutions in normal saline: clotting time of fresh plasma=9.5 sec.; clotting time of incubated plasma $=29$ sec. 
obtained by this method was found to be smoother and more regular. This can be seen by comparing Fig. 1, in which a 1 in 1 dilution was used, with Fig. 2, in which a 9 to 1 proportion was used. As stated previously, the reason for the smoother curve obtained with a 1 in 1 dilution was considered to be the greater degree of accuracy possible in measuring quantities of $0.2 \mathrm{ml}$. compared with $0.02 \mathrm{ml}$. for Stefanini's experiment.

\section{Theoretical Considerations}

Owren (1947d) has stated that incubation of plasma containing a $100 \%$ prothrombin complex concentration at $37^{\circ} \mathrm{C}$. for 30 minutes causes no deterioration in the factor $\mathrm{V}$ content. Investigations into a more prolonged incubation of the plasma at this temperature were not recorded. It has also been determined (Owren, 1947d) that incubation at $58^{\circ} \mathrm{C}$. of fresh, normal, oxalated plasma causes coagulation of fibrinogen as well as destruction of factor $V$. It was therefore necessary to show that incubation of the plasma for 24 hours at $37^{\circ} \mathrm{C}$. caused a deficiency of factor $\mathrm{V}$ to develop but did not affect the prothrombin or fibrinogen content.

Stefanini had already shown that the stored plasma was deficient only in factor $\mathrm{V}$, and, since plasma which had been incubated at $37^{\circ} \mathrm{C}$. for 24 hours showed identical behaviour in all the tests performed, it was assumed to have a similar composition. The following experiments demonstrate this.

If the stored plasma with a prolonged clotting time is mixed with the incubated plasma, which also shows a prolonged clotting time volume for volume, and a Quick's one-stage prothrombin test is performed on $0.2 \mathrm{ml}$. of the mixture, there is no shortening of the clotting time, i.e., it will be longer than the shorter of the two separate clotting times. Therefore it is concluded that neither plasma is able to supply a factor which is deficient in the other.

The following series of results were obtained for experiments comparing the effect of plasma from a patient on dicoumarol therapy on the stored and incubated plasmas (Table II).

It can be seen from Table II that dicoumarolized plasma, when mixed with normal fresh plasma, volume for volume, behaves in the same way as water does. But when dicoumarolized plasma is mixed volume for volume with either stored or incubated plasma the effect is the same as if the fresh plasma had been diluted to $50 \%$ with water. The behaviour of the stored and incubated plasmas is therefore identical and the fuller implications of this result are discussed later.

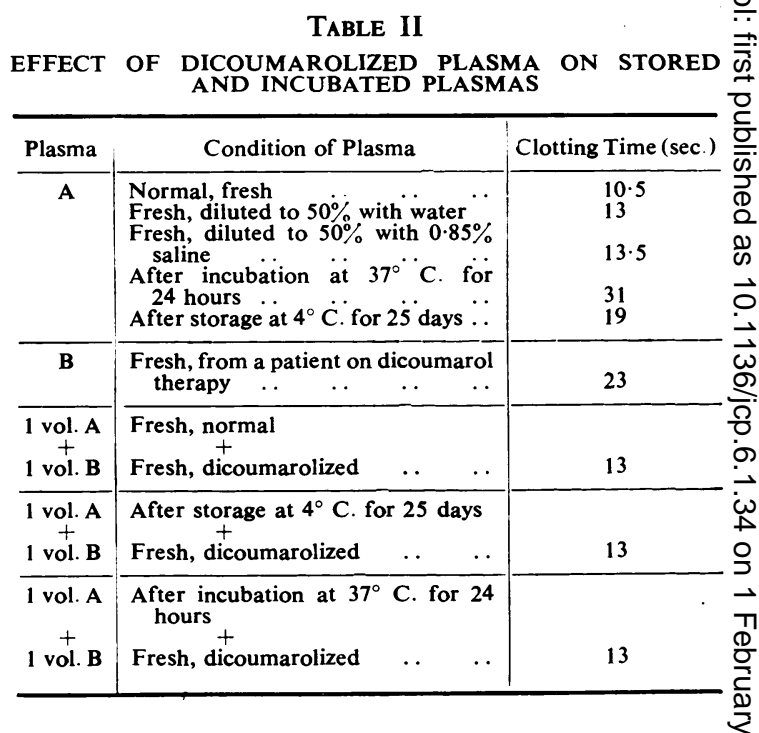

In the second experiment fibrinogen was added $\vec{\oplus}$ to a plasma which had been incubated at $37^{\circ} \mathrm{C}$. for 24 hours and showed a prolonged clotting time. The new clotting time was then found, using Quick's one-stage prothrombin test, and was found to be still as prolonged. It was therefore $\bar{O}$ concluded that the incubated plasma was not deficient in fibrinogen.

Thirdly, an incubated plasma which had a $\overrightarrow{\vec{O}}$ clotting time of 37 seconds by Quick's one-stage 3 prothrombin test was mixed volume for volume with a fresh normal plasma which had a clotting? time of 10 seconds, and the new clotting time of the mixture was determined using Quick's one-? stage test. This was found to be between 11.5 and 3 . 12.5 seconds. Previous experiments had shown that if one of the plasmas in a mixture contained 3 an anticoagulant then the clotting time of the mix-o ture was considerably prolonged. It was therefore concluded that an anticoagulant was noto present in the incubated plasma.

It can be seen from Table II that if a fresh plasma from a patient on dicoumarol therapy with a low prothrombin complex concentration was N mixed volume for volume with the incubated ${ }_{\sigma}^{\omega}$ plasma and a Quick's one-stage prothrombin test done on the mixture, the clotting time was always about 11.5 to 13 seconds, although the separates? clotting times of the two plasmas were much $_{\vec{D}}^{+}$ greater than this. A similar clotting time was alsoobtained if the incubated plasma was mixedī volume for volume with a normal fresh plasma $\frac{\rho}{\mathrm{D}}$ It seems apparent that, although both the dicou 0 marolized and the incubated plasma were deficient in some factor which caused them to have a pros 
longed clotting time when alone, these two factors were different. Therefore when the two plasmas were mixed each provided the factor that was deficient in the other and so produced a shortened clotting time. The actual clotting time corresponded to a $50 \%$ dilution of normal fresh plasma with water. The clotting time obtained in this experiment was always between 11.5 and 13 seconds, no matter how severe the prothrombin deficiency was in the dicoumarolized plasma, provided there was no deficiency of factor $V$. As it has also been found that if two prothrombin-deficient plasmas are mixed volume for volume the prothrombin clotting time of the mixture was always greater than the shorter of the two separate clotting times, it was concluded that the incubated plasma was not deficient in prothrombin and therefore it could only be deficient in factor $\mathrm{V}$ or a related accelerator complex.

To illustrate that the plasma incubated at $37^{\circ}$ C. for 24 hours was deficient in factor $\mathrm{V}$, plasma $P$ was incubated for 24 hours at $37^{\circ} \mathrm{C}$., when it gave a clotting time of 35.5 seconds by Quick's one-stage test (when fresh it gave a clotting time of 10 seconds). It was then mixed, volume for volume, with different normal fresh plasmas and plasmas from dicoumarolized patients, when the following results were recorded (Table III).

TABLE III

FACTOR V DEFICIENCY IN PLASMA INCUBATED AT $37^{\circ} \mathrm{C}$. FOR 24 HOURS

\begin{tabular}{c|c|c|c}
\hline Plasma & $\begin{array}{c}\text { Condition } \\
\text { of Plasma }\end{array}$ & $\begin{array}{c}\text { Clotting Time } \\
\text { Alone (sec.) }\end{array}$ & $\begin{array}{c}\text { Clotting Time when } \\
\text { Mixed (vol./vol.) } \\
\text { with Incubated } \\
\text { Plasma V (sec.) }\end{array}$ \\
\hline $\mathbf{W}$ & $\begin{array}{l}\text { Normal, fresh } \\
\text { Xrom a well dicou- }\end{array}$ & $10 \cdot 5$ & $11 \cdot 8$ \\
marolized patient \\
Z & $\begin{array}{l}\text { Normal, fresh } \\
\text { From a dicoumarol- } \\
\text { ized patient with } \\
\text { heart failure }\end{array}$ & 10 & 13 \\
\hline
\end{tabular}

Plasma $\mathrm{Z}$ has behaved differently from plasma $\mathrm{X}$ although both were from dicoumarolized patients. Plasma $X$ from its clotting time when alone shows a more severe prothrombin complex deficiency than plasma $Z$, yet when plasma $X$ is added to the incubated plasma it is able to restore its clotting ability to a greater extent than plasma $Z$. Both plasmas $X$ and $Z$ gave a clotting time of 12 to 13 seconds when mixed volume for volume with normal fresh plasma, and only when mixed with stored or incubated plasma was any difference in behaviour detected. It appears, therefore, that plasma $X$ possesses a restoring power which is deficient in plasma $Z$, so that plasma $Z$ must be deficient in the same clotting factor as was the incubated plasma. This is assumed to be factor $\mathbf{V}$ or a related accelerator complex.

\section{Errors Preventing Consistent Results}

To obtain consistent results it is necessary that a plasma without a full prothrombin complex concentration before incubation must not be used as the source of factor-V-deficient plasma, and the plasma must not be incubated for more than 24 hours. Over-incubation of the plasma was shown to produce a prothrombin deficiency as well as a factor $\mathrm{V}$ deficiency.

The following experiments were done with plasmas which had been incubated for different lengths of time to demonstrate that 24-hour incubation of normal fresh plasma at $37^{\circ} \mathrm{C}$. diminishes the factor $\mathrm{V}$ content but not the prothrombin content, while longer incubation diminishes both.

In three experiments, plasmas $\mathrm{D}, \mathrm{E}$, and $\mathrm{F}$ respectively, which when fresh showed clotting times of 10 or 10.5 seconds, were incubated at $37^{\circ}$ C. for different periods. From plasma D, incubated for 60 hours, no clot could be obtained by Quick's one-stage test up to 30 minutes. Plasma E was incubated for 48 hours, when it gave a clotting time of 60 seconds by Quick's one-stage test, and plasma $F$ incubated for 24 hours gave a clotting time of 35.5 seconds by the same test. After the first reading of the clotting times each incubated plasma was mixed, volume for volume, with several samples of plasma and the clotting times of the mixtures recorded by Quick's onestage test (Table IV).

TABLE IV

CLOTTING TIMES OF FRESH PLASMAS AFTER MIXING WITH THREE PLASMAS INCUBATED FOR DIFFERENT PERIODS

\begin{tabular}{|c|c|c|c|}
\hline & $\begin{array}{l}\text { ition } \\
\text { sma }\end{array}$ & $\begin{array}{l}\text { Clotting Time } \\
\text { Alone (sec) }\end{array}$ & $\begin{array}{l}\text { Clotting Time when Mixed } \\
\text { (vol./vol.) with Plasmas } \\
\text { after Incubation at } \\
37^{\circ} \mathrm{C} \text {. (sec.) }\end{array}$ \\
\hline \multicolumn{4}{|c|}{ Plasma D Incubated for 60 Hours } \\
\hline \multicolumn{2}{|c|}{$\begin{array}{l}\text { Normal, fresh } \\
\text { Fresh, dicoumarolized }\end{array}$} & $\begin{array}{l}10 \\
16\end{array}$ & \multirow{3}{*}{$\begin{array}{l}12 \cdot 5 \\
17 \cdot 5 \\
20 \\
27\end{array}$} \\
\hline$\ddot{\prime \prime}$ & , & $\begin{array}{l}24 \\
28\end{array}$ & \\
\hline \multirow{2}{*}{\multicolumn{4}{|c|}{ Plasma E Incubated for 48 Hours }} \\
\hline & & & \\
\hline \multicolumn{2}{|c|}{$\begin{array}{l}\text { Normal. fresh } \\
\text { Fresh, dicoumarolized }\end{array}$} & $\begin{array}{l}10 \\
15.5\end{array}$ & \multirow{3}{*}{$\begin{array}{l}12 \cdot 1 \\
17 \\
15 \\
18\end{array}$} \\
\hline , & , & 16 & \\
\hline ," & , & & \\
\hline \multicolumn{4}{|c|}{ Plasma F Incubated for 24 Hours } \\
\hline \multicolumn{2}{|c|}{$\begin{array}{l}\text { Normal, fresh } \\
\text { Fresh, dicoumarolized }\end{array}$} & $\begin{array}{l}10 \cdot 5 \\
21\end{array}$ & \multirow{4}{*}{$\begin{array}{l}12 \\
13 \cdot 5 \\
12 \\
14 \\
13\end{array}$} \\
\hline , & , & 26 & \\
\hline$\ddot{\prime \prime}$ & , & 65 & \\
\hline ", & $"$ & & \\
\hline
\end{tabular}


By comparing these three experiments it can be seen that, provided the factor-V-deficient plasma is not deficient in prothrombin either initially or through over-incubation, consistent results are obtained for the mixed clotting times which are quite uninfluenced by the severity of the prothrombin deficiency of the dicoumarolized plasma. Plasmas that are over-incubated or are deficient in prothrombin before incubation are useless for estimating factor $V$, as the clotting time of the mixture is influenced by a pure prothrombin deficiency of the plasma tested. This method will also identify factor $\mathrm{V}$ deficiency in a dicoumarolized plasma.

Factor $\mathrm{V}$ and prothrombin estimations are done in this laboratory in all cases where liver function tests are required. The method is simple and gives consistently good results, provided the conditions stated are closely adhered to and that an anticoagulant is not present. In all cases which show an abnormal result a test for anticoagulants is carried out by testing for a prolongation of clotting time when the plasma is mixed with a normal fresh plasma. As with Quick's one-stage prothrombin test, a separate graph must be made for each batch of new thromboplastin used. In reporting results those between $0 \%$ and $50 \%$ are reported to the nearest $5 \%$, but it can be seen from the type of graph obtained that a more detailed result in the $50 \%$ to $100 \%$ range is not necessary.

\section{Summary}

A modification of Stefanini's method of esti- $\vec{\circ}$ mating factor $\mathrm{V}$ activity in human oxalated plasma is described which is claimed to be more sensitive and easier to perform. This method has given consistently good results with numerous daily estimations over a period of more than two months.

My thanks are due to Dr. J. Davson for helpful $\stackrel{\circ}{\triangle}$ criticism in preparing this paper.

REFERENCES

Owren, P. A. (1947a). Acta med. scand., Suppl. 194, 76.

(1947b). Ibid., 24.

(1947c). Ibid., 127

(1947d). Ibid., 85.

Quick, A. J. (1936). Amer. J. Physiol., 115, 317.

Q (1943). Ibid., 140, 212.

(1947). Ibid., 151, 63.

and Stefanini, M. (1948). J. Lab. clin. Med., 33, 819.

Stefanini, M. (1951). Lancet, 1, 606. 